\title{
Historiografía y hagiografía: vidas ejemplares y escritura de la historia en el Nuevo Reino de Granada ${ }^{1}$
}

\author{
Jaime Humberto Borja Gómez \\ Pontificia Universidad Javeriana, Colombia \\ borja@javeriana.edu.co
}

\section{Resumen}

Del conjunto de textos escritos entre los siglos XVI y XVIII, los historiadores de los siglos XIX y XX escogieron las crónicas como las únicas representantes de la escritura de la historia. Esto implicó la exclusión de otros textos, como las "vidas ejemplares", que en su momento formaban parte del corpus de la historia, pero que fueron invalidados por una lectura positivista, debido a que planteaban hechos "prodigiosos", que se consideraban cargados de una alta dosis de ficción. Este género de origen medieval, vivificado por la hagiografía barroca, se empleó para destacar a aquellos sujetos coloniales neogranadinos que las instituciones o las creencias populares erigieron como ejemplos de vida y, por extensión, en la representación de un modelo de comportamiento sobre el cual se debía construir discursivamente el sujeto ideal. La escritura de estos textos se hizo desde las reglas de la retórica de la historia. El presente artículo busca devolver a su horizonte de producción estas narraciones, con lo cual se pretende destacar la pertenencia de la hagiografía al género historiográfico.

Palabras clave: hagiografía, historiografía, siglos XVI y XVII, vidas ejemplares, retórica, sujetos coloniales.

\begin{abstract}
From the group of texts written between the 16th and 18th centuries, historians of the 19th and 20th centuries chose the chronicle as the only genre that belonged to the writing of history. This led to the exclusion of other genres, such as "exemplary lives", which, by the time they were written, formed part of the corpus of history. They were invalidated by a positivistic reading that found a high dose of fiction in the "prodigious" facts that they narrated. Exemplary lives - genre of medieval origin revived by the baroque hagiography-were

\footnotetext{
${ }^{1}$ Esta investigación contó con la financiación de Colciencias y la Pontificia Universidad Javeriana.
} 


\section{FRONTERAS}

de la historia

used in the New Kingdom of Granada to make those local colonial subjects stand out that were erected as role models either by institutions or by popular belief. By extent, these role models evolved in representations of models of behavior upon which the "ideal subject" had to be constructed discursively. These texts were written under the rules of the rhetorical writing of history. This article aims to reestablish the connection between these narrations and the horizon of their production, and, thus, to stress that hagiography belonged to the historiographical genre.

Key words: Hagiography, historiography, $16^{\text {th }}$ century, $17^{\text {th }}$ century, exemplary lives, rhetoric, colonial subjects.

\section{Introducción}

El 8 de septiembre de 1654 murió en Cartagena en fama de santidad el jesuita Pedro Claver. La documentación que existe sobre este acontecimiento coincide en afirmar el impacto que causó su muerte ${ }^{2}$ : gente se arremolinó frente al lugar donde era velado para tomar como reliquia algún objeto que hubiese estado en contacto con él y hubo que montar guardia para evitar que el cuerpo fuese destrozado:

No se vaciaba la Iglesia de la mucha gente que entraba y salía; y cerca del anochecer fue tal el concurso, y las olas de innumerables negros y negras y personas del pueblo y la comarca, que envistieron sobre el cuerpo, que se temió no lo hiciesen pedazos, según era el tropel y vehemencia para tocarle y verle. (Fernández 640-41).

Las muestras de dolor se prolongaron por varios días; a su entierro asistieron todas las autoridades, civiles y eclesiásticas, y la memoria de este hecho estuvo presente en los siguientes siglos. Tumultos similares se registraron en Santafé casi 70 años después, tras la muerte de la carmelita Francisca del Niño Jesús o de la inesita Gertrudis de Santa Inés (Calvo de la Riba 559; Villamar 349). Estos casos, que no eran aislados, revelan la importancia de ciertos personajes coloniales cuyas vidas se han perdido para los intereses de la reciente historiografía, pero que en su momento tenían el estatuto de "héroes" y eran reverenciados como tales.

\footnotetext{
${ }^{2}$ Entre algunas fuentes de la época se pueden tener en cuenta: "Proceso", "Testimonio", Andrade, Cassani, Fernández y Splendiani.
} 
En las sociedades coloniales, donde la distancia entre lo sagrado y lo profano era muy difusa, el ideal de comportamiento aún era la santidad, a pesar que se debatían entre la tensión de los avances del individualismo, la secularización y la pervivencia de la visión sacralizante de la realidad. Tener un santo propio se convirtió, a lo largo y ancho de América colonial, en una aspiración de cualquier ciudad, lo que incluso llegó a despertar competencias entre los virreinatos (Rubial 67). Esto explica el esfuerzo político y económico que llevaban adelante los cabildos civiles y eclesiásticos para adelantar estas causas de fe en Roma, con el fin de que sus muertos en santidad fueran reconocidos oficialmente como santos de la Iglesia católica. Aunque la única causa neogranadina que tuvo éxito fue la de Pedro Claver, beatificado ${ }^{3}$ en 1850 , se adelantaron otros procesos: además de las dos monjas ya citadas, el arzobispo Bernardino de Almansa, fallecido en Villa de Leiva en 1633; la laica tunjana Antonia Cabañas, muerta en 1667; la criolla Francisca de Zorrilla, esposa del oidor y escritor colonial Gabriel Álvarez de Velasco, y la monja Juana de San Esteban, por mencionar algunos casos.

Para iniciar el proceso jurídico de estos sujetos llamados "ejemplares", no sólo por las autoridades, sino también por el común de la gente que los veía como modelos de comportamiento, se exponían públicamente sus vidas ante la sociedad en un género de literatura edificante, las vidas ejemplares, en las cuales un autor recogía su biografía, según las normas de la escritura de la historia, para el conocimiento y ejemplo de sus contemporáneos. Durante los siglos XVII y XVIII, en el Nuevo Reino de Granada se escribió una apreciable cantidad de libros que narraban las vidas de este tipo de personas. La aparición de estos textos respondió a la consolidación de los diversos espacios culturales del Reino que no sólo eran consecuencia de las transformaciones políticas o las nuevas dinámicas económicas: las narraciones de las vidas ejemplares eran mecanismos culturales que pretendían modelar idealmente comportamientos $\mathrm{y}$ prácticas sociales. Estos discursos pretendían crear una representación de cuerpo "individual" y, por medio de éste, la formación de un cuerpo social, estrategia dirigida a la formación de lo que hoy llamaríamos "sujetos barrocos".

Los santos significaban más que devoción: histórica y culturalmente, son una representación del sujeto ideal para una sociedad. Por esta razón, el concepto de santidad cambia y se adecúa a los esquemas de valores y a las formas como se percibe la conformación discursiva de los sujetos que deben hacer parte de un

\footnotetext{
${ }^{3}$ La beatificación era el paso previo para la canonización. Consistía en una declaración pública papal una vez concluida una parte del proceso, lo cual autorizaba a culto y rezo privado.
} 


\section{FRONTERAS}

de la historia

cuerpo social particular. En este sentido, las vidas ejemplares son exactamente eso: vidas que una cultura propone como modelos de comportamiento, las cuales representan, a su vez, la jerarquía de los valores que esa sociedad determina como base de sus relaciones individuales y sociales. En palabras de Certeau:

La vida de un santo se inscribe dentro de la vida de un grupo, Iglesia o comunidad; supone a un grupo ya existente, pero representa la conciencia que éste tiene de sí mismo al asociar una figura a un lugar [...] la vida de un santo es la cristalización literaria de las percepciones de una conciencia colectiva. (260)

La escritura de las vidas ejemplares se constituye, entonces, en los artefactos narrativos con los que se pretende modelar la subjetividad, como también representa las ideologías y los discursos acerca de cómo deben ser y cómo se deben comportar los sujetos, en este caso, coloniales.

En el Nuevo Reino de Granada, los sujetos ejemplares de los siglos XVII y XVIII representaron modelos de comportamiento ideales que, de acuerdo con el discurso, debían ser imitados. Es aquí donde Almansa, María Gertrudis, Antonia, Francisca del Niño Jesús o cualquier otro individuo ejemplar dejaba de ser sólo un sujeto importante para sus contemporáneos, y pasaba a convertirse en la representación de un modelo de comportamiento sobre el cual se construía discursivamente el sujeto ideal. Los autores de sus biografías participaban activamente en el proceso, porque a partir de su mundo y su cultura daban forma narrativa a un conjunto de valores que caracterizaban al sujeto ideal.

Con esta problematización encontramos, entonces, dos campos diferenciados: por un lado se encuentra la idea de santidad, y por otro, la escritura de esa santidad. Si la historia de la idea de santidad no es uniforme, lo mismo sucede con la escritura de esa santidad, conocida con el nombre de hagiografía, pues está supeditada a normas y modelos que regulan su escritura.

Actualmente el término hagiografia hace referencia a los textos que recogen las narraciones de las vidas de los santos o, por extensión, a aquellos donde se narran las vidas de sujetos ejemplares ${ }^{4}$. Además, la hagiografía se entiende como un tipo de relato que se opone a nuestra actual idea de historia, en la medida en que los códigos que empleamos para establecer la tipología de lo que

\footnotetext{
${ }^{4}$ La bibliografía acerca de los estudios históricos sobre la hagiografía es amplia. A manera de introducción se puede ver el texto clásico de Delehaye, principalmente el capítulo 4; también, Dubois y Lemaitre, Sánchez ("Hechura” 336-352) y Stica.
} 
se considera pensar y escribir el pasado provienen de las determinaciones del positivismo del siglo XIX. Éste aportó la idea de que la historia se debía escribir a partir de tres códigos: relatar hechos, exponer verdades —en el sentido moderno del término - y ser objetiva. De acuerdo con estos criterios, del conjunto de textos escritos en el Nuevo Reino entre los siglos XVI y XVIII, los historiadores colonialistas de los siglo XIX y XX escogieron el llamado género de las crónicas como las únicas representantes de la escritura de la historia porque se acercaban a los códigos de verdad, objetividad y hecho. Esto implicó la exclusión de otros textos, como las vidas ejemplares, que en su momento formaban parte del corpus de la historia, pero a los cuales la lectura positivista invalidó debido a que planteaban hechos prodigiosos o maravillosos, es decir, con una gran dosis de ficción. Sin embargo, aquí estriba el problema, porque las condiciones que establecen qué es verdad o cuáles son los límites de la realidad dependen de cada cultura y de la manera de asimilar lo que es histórico. Esta pertenencia de la hagiografía al género historiográfico es lo que deseo demostrar en las siguientes páginas.

\section{La escritura hagiográfica}

Las posiciones acerca del sentido de la hagiografía, qué es y cuáles son sus límites han generado un gran debate que aún no concluye, pese a que es un área fuertemente descuidada por los historiadores, porque no ven en ella una relación directa con la historia. Para el caso neogranadino es importante plantear el debate porque la hipótesis que se pretende demostrar es que la llamada hagiografía es una forma de escribir la historia y que esta forma de escribirla tiene para su momento de producción un mayor sustento argumentativo que otros géneros considerados tradicionalmente "históricos", como la crónica. Además, es importante tener en cuenta que la hagiografía es un mecanismo de conciencia criolla, sobre el cual se articulan la posibilidad y la responsabilidad de generar una representación del ideal de sujeto colonial. Hay dos puntos de partida: el carácter de género que tiene la hagiografía para el siglo XVII —pues la mayor parte de los autores que han tratado el problema coinciden en que la hagiografía es un género literario que para esta época se le llamaba hagiología o hagiológica - y los significados históricos de escribir acerca de la santidad (Certeau 257; Ruffinatto).

Este último punto de partida es especialmente importante, porque, al igual que lo que ha sucedido con la idea histórica de santidad, su escritura ha estado en 


\section{FRONTERAS}

de la fistoria

permanente cambio ${ }^{5}$. La hagiografía como el acto de narrar las historias de santos surge hacia el siglo IV. En aquel entonces se diferenciaba la narración de los mártires, de quienes se contaba su muerte, de las narraciones que se hacían de los obispos, cuyo eje era sus vidas. Además, estos relatos tuvieron una fuerte influencia clásica, pues se tomaron como modelos los sistemas narrativos para hacer biografía o vidas paralelas propuestos principalmente por Plutarco y Suetonio. La función de estos textos estaba dirigida a mostrar las virtudes de los santos como mecanismo de cristianización en el proceso de expansión alto medieval del cristianismo. Por eso, estos textos también se introdujeron y utilizaron en la liturgia e iban dirigidos a predicadores. Sólo hasta el siglo X, en el contexto de la aparición de las santificaciones canónicas, las vidas de santos incorporaron el milagro como prueba de santidad y se estableció un nexo más poderoso entre aristocracia y santidad. Después del siglo XII surgieron nuevos temas en las narraciones, en buena parte debido a la aparición de los nuevos actores de santidad. Por ejemplo, la introducción en la espiritualidad del tema de la encarnación de Cristo permitía que se narraran aspectos más humanos y cotidianos de los santos, como su procedencia familiar, infancia y adolescencia.

Hacia el siglo XIV, las narraciones son influidas por las novelas históricas y los temas de caballería, de modo que las hagiografías se convierten en historias más épicas y sus temas consideran más la espiritualización del cuerpo. No hay que olvidar la fuerza e importancia de las leyendas áureas, como la de Santiago de la Vorágine, lo cual favoreció un proceso de vulgarización en el sentido de buscar un público más amplio y no sólo entre predicadores, lo que tendría una influencia importante en los siglos XVII y XVIII. La narración barroca recogió estos elementos y los fusionó con los aportes que hizo el humanismo del siglo $\mathrm{XV}$, de modo que el resultado fue un modelo diferente de narración. En primer lugar, se exalta el individualismo de manera que se plantea más una biografía con estructura retórica que un patrón al estilo medieval. En segundo lugar, se narran más las acciones que las contemplaciones de los santos; las virtudes ocupan un puesto más importante y pierde fuerza el milagro, que había sido tan importante en la Edad Media. Finalmente, se busca hacer un retrato de las motivaciones psicológicas de las acciones humanas, pues es una preocupación muy barroca el mundo de las acciones y las decisiones (Rubial 38; Sánchez, Mujeres 403-59). Como novedad, la hagiografía femenina tuvo una especial difusión.

\footnotetext{
${ }^{5}$ Un acercamiento al proceso histórico de santidad puede verse en Rubial, capítulo "Función social de los santos".
} 
Frente a estos cambios barrocos, hay que tener en cuenta una última cuestión que no sólo actúa como contexto, sino que problematiza el lugar donde se encuentran nuestras narraciones porque revela una mentalidad diferente: los bolandistas. Éstos fueron una sociedad de eruditos jesuitas liderados por Jean Bolland, que se dedicaron a expurgar el santoral, especialmente de santos de los primeros tiempos del cristianismo, que no tenían una procedencia muy clara. Para ello reunieron cuantas fuentes pudieron encontrar y trataron de documentar la vida de estos sujetos, un claro paso de la verdad dogmática a la verdad histórica (Bouza 81). Los bolandistas reflejaban una nueva actitud frente a la narración de santos o ejemplares, y ponían de manifiesto la relación que tiene la hagiografía como perteneciente a un género.

De esta forma, el término hagiografia ha sido utilizado historiográficamente de forma más o menos arbitraria para definir la escritura de la vida de los santos, y desde allí se asimila con diferentes estilos y formas de narración. Lavrin, por ejemplo, ve en la hagiografía un modelo de difusión de la mística y la ascética desde el siglo XII, y define como "Género que combina lugares, personas, temas, hechos reales y sobrenaturales de acuerdo a un esquema conceptual de virtudes y milagros que fueron plasmados más tarde en los ya conocidos escritos de los místicos españoles de los siglos XVII y XVIII" (5).

Se trata de una definición que parte de la mirada como experiencia contemporánea, que pretende agrupar textos con ciertas características narrativas dentro de una tipología, que poco corresponde con el espacio en que fue producido el texto. De hecho, como ya se ha mostrado, la llamada hagiografía de la Edad Media no es la misma que la del Barroco. En cuanto al sentido, también se ha querido incorporar la hagiografía al género biográfico, para lo cual es importante tener en cuenta que durante la Edad Media no había diferencia entre la narración de la vida de un venerable, un laico, las novelas de caballería o la biografía caballeresca. La hagiografía no existía como concepto que refiriera a un género literario, ni tenía criterios que la diferenciaran de otras escrituras históricas (Durán 9-10, 26-33). Una característica de las tipologías de escritura es que reactualizan sus códigos de funcionamiento en relación con los tiempos y espacios que lo propician.

Para el caso neogranadino, las narraciones hagiográficas prácticamente no han llamado la atención. Gómez Restrepo incluye los relatos hagiográficos de vidas ejemplares dentro del género de las biografías; se nota en este autor un criterio de clasificación tipológica correspondiente al momento en que escribe: 


\section{FRONTERAS}

de la historia

Nuestras biografías coloniales, no muchas en número, corresponden al género religioso, y son, salvo alguna excepción, vidas de monjas escritas con tanto fervor como ingenuidad, y dedicadas a presentar eximios ejemplos de virtud y penitencia a la imitación de las almas piadosas. (269)

Según Gómez Restrepo, estos textos carecen de un criterio que haga la distinción entre "lo verdaderamente grande" de estos sujetos y los "pormenores mínimos y rasgos pueriles", así como la ausencia de arte literario que dé atractivo a la narración. El problema es que ni lo uno ni lo otro formaba parte de las expectativas de los autores. En primer lugar, porque exactamente eso es lo que no pretendían hacer, una biografía; sus intenciones eran narrar, como sus títulos lo indican, la vida y las virtudes, lo que no implicaba hacer un retrato psicologista brillante del sujeto, como pretende la moderna biografía. En segundo lugar, no escribían desde los códigos modernos de la literatura, sino desde perspectivas historiográficas barrocas.

Lo que queda claro en este contexto es la importancia de partir de un supuesto: la hagiografía como relato de vidas ejemplares no se puede encerrar en un género particular llamado "hagiografía", no sólo porque en el momento en que se producen los textos sus autores no están escribiendo desde la pertenencia a este género, sino también porque este término aún no existe. Sus discursos echan mano de unos conceptos particulares — verdad, fuente, historia- que están estrechamente relacionados con la tipología historiográfica vigente en los siglos XVII y XVIII, de manera que su discurso va de la mano de un género, la historia, que en aquel momento formaba parte de la literatura. Veamos algunos argumentos.

\section{La hagiografía entre retórica, historia y literatura}

Este recorrido introductorio sobre la condición como género y las diferentes vertientes que han modelado la hagiografía pone de relieve el primer punto de debate: ¿es historia o literatura? La tendencia historiográfica actual, ve la hagiografía como un "género" más cercano a la literatura que a la historia. Para Antonio Rubial, por ejemplo, el cambio de la hagiografía hacia formas más literarias se debió a las influencias que recibió entre los siglos XI y XV, especialmente por el impacto de la crónica histórica y la novela de caballería. Influencia que no cambió su acento literario, antes bien, lo consolidó y por esta misma condición puso la hagiografía al servicio de la liturgia y la predicación (30-32). En esta misma línea se encuentra Certeau, para quien la hagiografía no se puede dejar de considerar "En función de la 'autenticidad' o del 'valor 
histórico': y al hacer esto sometemos un género literario a la ley de otro - la historiografía - y desmantelamos un tipo propio de discurso para no conservar sino el que no es" (258).

Esto quiere decir que el tratamiento de los lugares y tiempos de la hagiografía se diferencia de los de la historiografía, en que la primera trata lo ejemplar, no lo que realmente ocurrió. El punto de unión entre las dos sería que tratan "hechos" históricos con un procedimiento distinto.

Desde mi punto de vista, este último planteamiento acerca de la relación de la hagiografía con la historia y la literatura es parcialmente cierto, porque se está tratando la narración hagiográfica desde la función que tienen la historia y la literatura actualmente. Pero si tenemos en cuenta que estamos hablando de una sociedad colonial que no hace una separación tajante entre lo sagrado y lo profano, entonces tampoco hay una ruptura tan radical entre la historia sagrada (lo ejemplar) de la historia humana (los hechos). Aquí es donde se hace necesario devolver estos textos a su horizonte de expectativas y, aún más, a la dinámica que se establece entre las reglas europeas que operan la producción de este tipo específico de discurso, y sus "adaptaciones" regionales, es decir, a las condiciones culturales que posibilitaron las narraciones hagiográficas en la Nueva Granada —respuesta a un catolicismo que no es el europeo-.

Una primera pista para establecer esta relación, es el mismo término hagiografia, el cual no existe ni es nombrado como tal en ningún lugar de las vidas ejemplares neogranadinas. De hecho, no hay rastros de términos semejantes o asociados, como tampoco aparece en los diccionarios de los siglos XVII y XVIII, como el de Covarrubias o el de Autoridades, lo cual establece un problema: los autores no tienen conciencia de que están integrando sus textos a un género específico denominado "hagiografía". Por el contrario, escriben bajo la idea de que están haciendo historia.

Veamos algunos ejemplos de los escritores neogranadinos: Pedro Andrés Calvo de la Riba, al introducir la familia y la nobleza de la vida ejemplar de María Gertrudis de Santa Inés, dice "me hallo como historiador, obligado a tratar de ella" (4). Pedro Pablo de Villamor, en su texto sobre la venerable Francisca del Niño Jesús, comienza afirmando: "Costumbre es de historiadores, que tratan de personas ilustres en virtudes, hacer mención de su patria, como que a la dicha de nacer en un lugar, se debiera la virtud" (1). Esta conciencia de estar escribiendo historia cuando tratan la vida ejemplar de un sujeto, remite a la recuperación, en el sentido de historiar y hacer que el recuerdo de estas santas criollas no se 


\section{FRONTERAS}

de la fistoria

pierda, lo que se convierte en uno de los instrumentos con los cuales estos autores, todos criollos, comienzan a generar una conciencia de pertenencia, evaluación y rescate de su acervo cultural.

Un repaso por los títulos de las vidas ejemplares que se produjeron en el Nuevo Reino nos da una percepción más cercana al problema: en todos es común la palabra vida acompañada de un epíteto que da sentido a la forma como se va a narrar: epitome breve (resumen), apostólica y penitente, ilustre, exemplar, colección o historia (Álvarez de Velasco; Calvo de la Riba; Fernández; Palacios; Solano; Solís de Valenzuela). Algunos autores, como Pedro Mercado, aclaran en algunas partes de su texto que escriben una relación; Gabriel Álvarez, por su parte, alude a que su texto es instrucción y carta. En cualquiera de los casos, los términos están emparentados con la historiografía. De este modo, vidas ejemplares es el nombre más apropiado para acercarse a ellas, pues el término hagiografía como categoría o género clasificatorio propone un sistema de lectura que no parece corresponder a la intención de los autores. Estos textos pretenden narrar la vida de un sujeto ejemplar, no buscan una determinación hagiográfica, luego el término, y con él la práctica, no se encierra en estos espacios tipológicos.

Con estas precisiones, es claro que los autores escribieron "vidas" dentro del entorno de lo que se entendía por historia en los siglos XVII y XVIII. Fundamentalmente se trataba de una narración que pretendía mostrar vicios y virtudes, y entre cuyos objetivos no estaba contar verdades en el sentido moderno del término, sino moralizar a partir de verdades verosímiles, es decir, verdades creíbles ${ }^{6}$. Sólo fue hasta el siglo XIX cuando se estableció una tajante separación entre los campos de acción que pertenecían a la historia y a la literatura, separación muy relacionada con la definición positivista de "verdad", que se comenzó a diferenciar de "verosimilitud" y, por extensión, de ficción. Esto tiene varias implicaciones: la primera es que la historia, de acuerdo con la tradición clásica vigente en los siglos XVII y XVIII, era un género de la gramática (literatura) - así como la fábula o la prosa-, y por tanto, estaba regulada por la retórica. Las vidas ejemplares neogranadinas responden a esta expectativa, en la medida en que seguían de cerca las reglas establecidas por los tratados de retórica, no sólo los tres clásicos de rigor y de moda en aquellos siglos -Quintiliano, Cicerón y Aristóteles-, sino también los que se

\footnotetext{
${ }^{6}$ A cerca del carácter retórico de la narración de la historia en el siglo XVI, véase Mendiola (Retórica 317-334).
} 
produjeron en los siglos XVI y XVII ${ }^{7}$. La retórica proponía tres grados para lograr la persuasión: enseñar, divertir y mover, los mismos que son introducidos en las vidas ejemplares: enseñar verdades dogmáticas y virtudes, divertir al lector y mover los sentimientos, esto es, imitar. Martín Palacios, por ejemplo, dice que contará la vida de Juana de San Esteban:

[...] cuya vida y virtudes se tratará con el estilo de elocuencia, que divierta el entendimiento, sí con una sincera narración, que pueda mover, cuando no a su imitación (porque esto depende del divino auxilio) a lo menos a dar gracias al Señor, porque se digna ennoblecer nuestro continente, y país, con almas justas, poniéndonos a la vista unos espectáculos dignos de avergonzar nuestra indolencia, pues supieron aprovecharse de las misericordias divinas, y nosotros las miramos con indiferencia. (fol. $1 \mathrm{v}$ )

La historia como narración, y con ella las vidas ejemplares, formaba parte de la poética porque dependía del orden de la gramática (según la definición de Quintiliano: correcto empleo del habla y sus comentarios), tradición que mantuvo viva Isidoro de Sevilla para la Edad Media ${ }^{8}$. Sin embargo, las poéticas del siglo XV agruparon en "géneros" las obras literarias de acuerdo con las características comunes y el humanismo incluyó la poesía y la historia en el trivium medieval (gramática, retórica y dialéctica).

A partir de entonces, se consolidó el discurso historiográfico, cuyos elementos poco variaron durante los dos siglos siguientes. En este lugar se encuentra una segunda implicación: el discurso historiográfico medieval $-\mathrm{y}$ su influencia, al menos hasta el siglo XVIII-, reposó en la tradición de la Antigüedad ${ }^{9}$. La historia entendida como "narración de hechos" fue enunciada por los historiadores griegos y romanos, quienes además le otorgaron un método

\footnotetext{
${ }^{7}$ En los siglos XVI y XVII se publicaron muchos tratados a cerca de cómo escribir la historia, los cuales se estructuraban desde la retórica. Entre los autores más sobresalientes se encuentran Fox Morcillo, Juan Costa, Baltazar Céspedes, Luis Cabrera de Córdoba y fray Jerónimo de San José. A cerca de la relación entre retórica e historia, así como la producción y utilización de tratados para regular su escritura, puede verse Borja (capítulo 2).

${ }^{8}$ Respecto a la relación de gramática, retórica y poética y su aporte al occidente moderno, véase Lausberg (72-86). En cuanto a las diferencias y progresos de la retórica antigua y medieval, Curtius $(70,106-20)$.

${ }^{9}$ La permanencia de la visión medieval de la historia se debe al humanismo de los siglos XV y XVI. Los cambios acaecieron en la segunda mitad del siglo XVII debido a la revolución epistemológica y a la obra de Vico (Koselleck 49-66).
} 


\section{FRONTERAS}

de la historia

particular ${ }^{10}$. Así se evidenció en la Edad Media, y aún las crónicas de los siglos XVII y XVIII empleaban los métodos clásicos para la narración, más cuando desde el siglo XVI se había recuperado la tradición purista clásica, de modo que escribir historia era imitar correctamente a un maestro griego o romano. Las hagiografías neogranadinas compartían este espacio de producción textual, pues su estructura narrativa se regía por las normas de estilo, la ordenación retórica de las ideas y la imitación de los grandes historiadores de la Antigüedad, o de autoridades bíblicas; es decir, imitaban un modelo narrativo: Villamor (112) y Palacios (fol. 16r) recurren a Cicerón con frecuencia, mientras que Solís de Valenzuela, a Séneca.

Se trataba de recurrir a los códigos conocidos por los lectores para elaborar un discurso verosímil, desde el cual la historia se convertía en maestra de vicios y virtudes y alcanzaba su objetivo: enseñar. Por esta razón, la práctica de la historia en el siglo XVII y XVIII no se interpretaba necesariamente desde sucesos verídicos, sino desde la narración literaria en cuanto utilizaba la tradición clásica, bíblica y teológica para argumentar los "hechos" que percibía la experiencia (Spiegel 126). En el prólogo que hace Pedro Pablo de Villamor a la Vida de Francisca del Niño Jesús es explícito este proceder, lo cual es común a casi todos los textos:

Va adornado de doctrina, de las Divinas letras, y algunas humanas, erudición de los santos padres: porque aunque el rigor de la historia pide los estrechos sotos de una narración clara, y fiel de los hechos sin estos ornamentos; no obstante, como la santidad de la Vida es un ajuste a la Divina Doctrina, en quien se amoldan con perfección los buenos espíritus, y se pulen con la enseñanza de los doctores, me pareció conveniente exornar esta Vida con ellas, para que reconozcan que en los procedimientos de nuestra venerable Madre, conformo los aciertos de su vida con las verdades de toda sana doctrina.

La historia como relato no expresaba necesariamente realidades, sino representaciones del entorno social que se traducían en relación con la tradición escrita clásica y medieval. Villamor deja claro que su texto se inscribe en la historia, en lo que hoy llamaríamos género historiográfico; además, como está en juego la santidad de la biografiada, le es preciso recurrir a argumentos tomados de las autoridades.

\footnotetext{
${ }^{10}$ Herodoto afirmaba que se debía registrar lo que se percibía por la vista y el oído; Tucídides enfatizaba en la experiencia personal, y Polibio, en la habilidad para interrogar a testigos (Momigliano 141).
} 


\section{Magister vitae: lo que enseñan las vidas ejemplares}

Los tratados de retórica del período establecían las reglas para la escritura de la historia. En los siglos XVI y XVII se produjeron manuales con este objetivo específico, como los de Fox Morcillo, Juan Costa, Baltazar Céspedes, Luis Cabrera de Córdoba y fray Jerónimo de San José ${ }^{11}$. Estos fueron, precisamente, los textos que trasmitieron las reglas de la disciplina y los códigos del discurso a partir de una matriz común ${ }^{12}$. Dichas reglas, por lo general, se presentaban en el prólogo, donde ubicaban el género al que pertenecía el texto y orientaban al lector acerca de cómo debía leerlo. Los autores de las vidas ejemplares neogranadinas, desarrollaron en sus prólogos tres elementos característicos: por qué escribían esa vida virtuosa para su imitación, cuáles eran las fuentes que iban a emplear y cómo se incorporaba en un género, la historia, lo que iban a narrar. Calvo de la Riba en "Al devoto y piadosos lector" dice: "Esta singular muger, que anduvo el camino de los incomprehensibles Juicios del omnipotente Señor, no para averiguados, sí para muy venerados, es el objeto de esta Historia". Por su parte, Pedro Solís de Valenzuela, en el "Prologo al lector" de su Epitome, dice refiriéndose a su hermano Bruno, de quien él toma la relación:

Mucha parte del merecimiento de los varones grandes, pende del ingenio del que los aclama: mas en este miedo, y recelo, me sirve de consuelo, el ver que aqui no ha lugar este problema, quando pretendo hazer esta relación, no a fuer de retórico orador sino de verdadero coronista. [...] Y casi en lo mas de ella se halló presente [Bruno de Valenzuela], y fue testigo de vista, y quien observó con particular cuydado, aun las menores circunstancias de qualquier hecho: con ventajoso estilo, y de historiador excelente, que esa lo que le llama su inclinación, y aun su estilo, como se verá en lo succinto desta narración, que por adopcion, y por hermandad, y sangre publico por mia.

Solís de Valenzuela explicita el carácter de crónica de su vida ejemplar, pero también, para proporcionarle veracidad al texto, recurre a una de las más importantes "fuentes" que se empleaban en el siglo XVII para escribir la historia, el ser "testigo de vista". Además hecha mano de uno de los recursos retóricos más empleados, la captatio benevolentiae, captar la benevolencia del lector al presentarse como humilde condensador de una extensa historia que ha escrito su hermano.

\footnotetext{
${ }^{11}$ Sobre estos autores del siglo XVI y XVII, véase el resumen y el contexto que recogió Montero.

${ }^{12}$ Esta es la idea de metatexto que propone Mignolo para el caso de la escritura de Indias, el cual se puede definir como el conjunto de elementos que según sus practicantes definen y caracterizan la práctica de su escritura y la inscriben dentro de una determinada clase de discursos (360).
} 


\section{FRONTERAS}

de la historia

Estos autores emplearon el prólogo como era costumbre en cualquier autor del siglo XVII o XVIII, apoyándose en los elementos teóricos propuestos por Aristóteles y dirigiéndose al lector para tomar contacto con el público ${ }^{13}$. Los tratados teóricos sobre la escritura de la historia más conocidos de la época incluían el prólogo como la primera de las nueve partes integrantes del discurso histórico, por lo que era considerado fundamental para el relato ${ }^{14}$.

Los códigos de los sistemas de escritura del siglo XVII eran tan complejos, que el nombre que se le daba a este preliminar, proponía el "género" de la poética al que pertenecía el discurso y establecía la responsabilidad literaria del texto frente al público. En estos casos, los hagiógrafos evidenciaban a sus lectores las claves para que entendieran que su discurso pertenecía al "género historiográfico", lo cual indicaba su conciencia de un público receptor al que se le codificaba el texto.

¿A qué se referían estos autores al incluir las narraciones de estos sujetos ejemplares como historia? Como he mostrado en otro texto, para esta época no había una sola definición de historia (Borja cap. 2). Pero cuando los autores, tanto en sus prólogos como en el conjunto de paratextos -aprobaciones, censuras, dedicatorias, etc.-, recurren insistentemente a mencionar el carácter "virtuoso" de estos sujetos, en oposición a los vicios de la sociedad, ofrecen otra pista para entender cómo estaban incluyendo su discurso dentro del género historiográfico: la implícita idea del magister vitae de Cicerón.

La historia como "maestra de vida" se había convertido en una de las opiniones más difundidas en la historiografía española e indiana, en la que se pueden reconocer dos problemas: el significado etimológico de la palabra historia y el carácter ético o moral que se desprende del magister vitae. La palabra historia se definía en los siglos XVI y XVII recurriendo a su etimología griega istoreo, lo que conducía a una ambigüedad en su interpretación: para unos, historia era recibir información de sí mismo o de otros como "testigo de vista". Para otros, era el relato oral o escrito de la información recibida. Para hacer más complejo el panorama, la autoridad a la que más se recurrió para definirla fue al mismo Cicerón, quien decía que historia es "narración verdadera de hechos pasados". Esto se leyó de dos maneras: primero, historia como el dominio de los hechos pasados, llamado por los tratadistas res gestae, e historia como el texto que

\footnotetext{
${ }^{13}$ Aristóteles creó la teoría del exordio (prólogo) para cada uno de los tres géneros retóricos: judicial, deliberativo y demostrativo (Porqueras 21-43).

${ }^{14}$ Por ejemplo en Cabrera de Córdoba (96-98).
} 
recuperaba y organizaba los hechos en una narración, rerum gestarum (Mignolo 366-67).

Los textos ejemplares neogranadinos hacían uso de la palabra historia en ambos sentidos. En cuanto al sentido res gestae, lo hacían con la intención de ubicar a estos sujetos ejemplares dentro de una dinámica historicista, es decir, incluirlos e incluir a la patria dentro del "plan de salvación". Sin embargo, era más usual emplear la palabra historia en función del sentido rerum gestarum, es decir, como recuperación de los hechos en un texto más cercano al "contar una historia" que "hacer historia". En este contexto se interpretaba la historia de los sujetos ejemplares como maestra de vida, porque sus vidas revelaban virtudes y comportamientos dignos de ser imitados. Y precisamente esto era hacer historia en los siglos XVII y XVIII, como lo hacía la crónica, narrar acontecimientos que revelaban vicios y virtudes insertos en un escenario de tiempo y espacio, de modo que sirvieran para el bien vivir.

Desde la Antigüedad y la Edad Media, la literatura tenía una clara intención moral, porque debía estar al servicio de la instrucción y edificación del hombre. En las narrativas históricas del siglo XVII, esta intención era abordada por el docere (enseñar), uno de los grados de la persuasión retórica, técnica que, como hemos mencionado, fue empleada por los autores neogranadinos. Las hagiografías poseían una estructura cerrada, narraban el nacimiento del sujeto, sus tribulaciones, virtudes, milagros y, finalmente, la muerte, lo que la convertía en "la forma literaria más competente para infundir mensajes sociales y proyectar valores por su función de narrar vidas humanas" (Loreto 26; Rubial 42).

En el contexto de estos siglos, la historia se dividía en divina y humana, y esta última, en natural y moral. Por moral se entendía la "narración de los dichos y hechos. Esta es 'particular' que narra la vida, vicios y virtudes de alguno, y 'pública', que los hechos de muchos" (Cabrera de Córdoba 34) ${ }^{15}$. La definición remitía al tratamiento "técnico" que se le debía dar al relato desde el género demostrativo, por lo cual las narraciones hagiográficas cabían dentro de la clasificación de moral y particular, lo que de algún modo impide que se puedan interpretar como una biografía en el sentido moderno del término, pues el objeto de su narración era demostrar la virtud. Para el efecto, se elaboraba un discurso

\footnotetext{
${ }^{15}$ La mayor parte de los grandes metatextos establecen esta diferencia, que puede apreciarse también en la producción histórica, como en la obra de José de Acosta Historia natural y moral de Indias o en la de Fernández de Oviedo Sumario de la natural historia de las Indias.
} 


\section{FRONTERAS}

de la fistoria

verosímil, desde el cual la historia del ejemplar se convertía en maestra de virtudes y alcanzaba su objetivo, enseñar. La relación entre historia y moral daba sentido a todas las obras. Sus narraciones reseñaban virtudes, pero también vicios encarnados en aquellos sujetos con los que los virtuosos convivían cotidianamente. Estas personas representaban el egoísmo, la envidia, la tentación, es decir, estaban encargados de "probar" la templanza y humildad de los ejemplares. De este modo, al enfrentar las recompensas a los virtuosos y los castigos a los viciosos, se le insinuaba al lector la necesidad de que asumiera cambios en sus comportamientos (movere). Esto convertía la narración en magister vitae: la historia significaba corrección de vida.

\section{Modelos y fuentes hagiográficas}

En el contexto de lo que significaba escribir la historia, las vidas de santos y ejemplares introdujeron un importante cambio en cuanto al uso de las fuentes. Para entonces, las que más asiduamente se empleaban en la escritura de la historia eran el ya mencionado testimonio de vista, las autoridades (auctoritates) clásicas y bíblicas y eventualmente las relaciones. Si bien es cierto que existía una preocupación desde el siglo XVI por comenzar a utilizar documentos escritos para apoyar la argumentación, este problema se hizo más evidente en las narraciones de historias de santos o de candidatos a santidad. Esta necesidad surgió como consecuencia del conjunto de reformas que Urbano VIII introdujo a partir de 1625 , según las cuales se prohibía la impresión de libros que contuvieran sugerencias de santidad, milagros u otros dones que no fueran probados y que no contaran con la aprobación de la Iglesia, con lo que se pretendía frenar la introducción de mitos populares sobre estos sujetos y actitudes milagrosas que no se pudieran demostrar. Aunada esta posición con los efectos de la actividad bolandista, se fortalecieron tanto las exigencias para el procedimiento de beatificación y canonización, como la demostración documental de la vida del posible santo, especialmente lo que tenía que ver con sus potenciales milagros.

Ahora se necesitaban pruebas contundentes de santidad, demostradas con documentos jurídicos, testimoniales o administrativos, de manera que se justificara un posible proceso de santidad. En este sentido, las vidas ejemplares como escritura histórica no sólo recibían un tratamiento retórico donde los argumentos para demostrar la virtuosidad se disponían desde la inventio para proporcionarle un carácter verosímil, sino que hagiográficamente dichos argumentos debían ser verdaderos, pues estaba en cuestión la fe y la verdadera relación de los sujetos con las virtudes y los supuestos milagros. Las vidas 
ejemplares de estos sujetos eran historia porque estaban insertas dentro de un escenario real, con acontecimientos reales; además, pretendían instruir y construir a otros sujetos lectores a partir de normas que se elevaban a verdaderos comportamientos, y para convencerlos había que crear espacios de cotidianidad cercanos al lector.

Esta situación de la escritura de las vidas ejemplares es paradójica con respecto a la "acusación" de que la hagiografía es ficción. Si en el conjunto de las narraciones historiográficas escritas en el mismo periodo hay textos que trataban de fortalecer las afirmaciones - para lo cual sus autores hacían rigurosas investigaciones-, ésos son estas vidas ejemplares. Se trataba de una seria postura donde el autor se jugaba el carácter y la fama de santidad del sujeto, luego la verdad de su historia debía estar fuertemente respalda por documentos jurídicos, como documentos de exhumación y testamentos, declaraciones notariales y juramentadas de los testigos, y documentos escritos por el sujeto historiado, como cartas, fragmentos de sus autobiografias o apuntamientos. Solís de Valenzuela aclara en su prólogo las fuentes que utiliza:

Y assi te advierto o letor, que lo soy en esta obra de muchas cosas, que yo vi, oi y entendí, con mucha certeza, y de otras, que con toda legalidad he sacado de papeles auténticos, y informaciones jurídicas, que están en los Archivos Arzobispales de la Ciudad de Santa fe: y de relaciones fidedignas. Y lo principal de los escritos de mi hermano el Padre Don Bruno de Valenzuela Monge de la Real Cartuxa de Santa Maria del Paular [...].

Calvo de la Riba y Villamor citan además como fuente contextual a historiadores neogranadinos autorizados, como Juan Flórez de Ocariz, muy empleado para establecer las genealogías de sus biografiados, y a Lucas Fernández de Piedrahíta. Pero también estas narraciones de vidas ejemplares se unían a la narración tradicionalmente histórica, de origen clásico y medieval, en la medida en que recurrían a los ya conocidos testimonios orales y visuales, la fuente primordial del quehacer histórico durante los siglos XVI al XVIII. Y, por supuesto, no dejaban por fuera la fuente más empleada para la argumentación histórica y de uso común en el Nuevo Reino, las auctoritates clásicas y bíblicas, como también teólogos y filósofos medievales y modernos. En este sentido, el catálogo bibliográfico es verdaderamente sorprendente si se tiene en cuenta el tamaño de la Bogotá o Tunja coloniales y las dificultades para la circulación e importación de libros, pues cobijaba lectura y comentarios de filósofos e historiadores de la Antigüedad, como Tales de Mileto, Suetonio,Tito Livio, Plinio, Ovidio o Juvenal, hasta pensadores de diversos momentos e ideologías, como san Jerónimo, Ambrosio, Tertuliano, Valerio Máximo, Juan Eusebio 


\section{FRONTERAS}

de la historia

Nieremberg, Orígenes, Francisco de Sales, Miguel Godínez, por mencionar algunos. Las vidas ejemplares estaban compuestas por una compleja intertextualidad clásica, que intercalaba comparaciones de los hechos de los virtuosos con conocidas situaciones de la historia grecorromana, o también se trasladaba al escenario de la santidad pasajes tomados de éstas y muchas otras autoridades. Sólo basta un ejemplo: la vida de Francisca de Zorrilla escrita por el oidor Gabriel Álvarez de Velasco tiene 521 citas en las 168 páginas que componen el total del libro. Sin duda, estas vidas ejemplares también acercan al historiador a una historia de la recepción de la lectura colonial.

Si se comparan estas narraciones ejemplares con la producción más clásica de la historiografía neogranadina de la misma época, las crónicas, se puede notar la diferencia en cuanto a recursos de fuentes para la argumentación. Basta citar los ejemplos de Las noticias historiales, de Pedro Simón, o las crónicas de Fernández de Piedrahíta o Zamora, textos que aun a finales del siglo XVII seguían empleando como principal fuente lo oral y lo visual. El punto en común era que las vidas ejemplares, como las crónicas, hacían uso de la retórica para adornar las verdades enunciadas; esto no las acercaba a la ficción, sino que eran las reglas que se empleaban para el tratamiento de la materia.

Finalmente, hay que tener en cuenta que buena parte de las crónicas neogranadinas de los siglos XVII y XVIII solían incluir vidas ejemplares dentro de su narración. Cassani, Mercado y Zamora, entre otros, integraron dentro de sus descripciones históricas las vidas virtuosas - y hasta milagrosas - de sujetos coloniales que de acuerdo con su tratamiento narrativo se comportaban como menologios o elogios. Incluso Genealogías del Nuevo Reino de Granada de Flórez de Ocariz, obra muy utilizada hoy día, establecía como parte de su texto la narración de vidas ejemplares, porque en la mentalidad de la época no podía existir santidad sin nobleza o linaje (198-240). De esta manera los textos pretendían presentar cómo Dios mostraba su bondad al bendecir estas tierras con sujetos ejemplares y virtuosos. Así, no había una separación tajante ni de género entre historia y la llamada hagiografía, antes bien, eran espacios que confluían y se complementaban.

\section{Narrar la verdad}

Una de las críticas contemporáneas más fuertes que recibe la hagiografía es que narra ficción. Sin embargo, este es otro de los aspectos que se deben contextualizar, porque el examen de los prólogos permite acercarse a los sentidos que tenía narrar la verdad en un texto donde se jugaba la fama de 
santidad de un sujeto. Como lo mencionamos, las retóricas de la época y los tratados que reflexionaban sobre cómo escribir historia establecieron a los prólogos una doble función: por una parte, explicar cómo y por qué se debía leer el libro, y por otra, capturar la atención del lector, su benevolencia y docilidad, lo que en términos retóricos se denominaba la captatio benevolentiae. Se trataba de atraer la atención y disponer al lector sobre lo que iba a leer; allí residía la fuerza de la persuasión, porque el prólogo pretendía motivar al lector abriéndole el camino de la enseñanza (docere) por medio de la narración histórica, deleitarlo (delectare) para captar su simpatía y originarle una conmoción psíquica, literalmente, mover (movere) el pathos, los sentimientos (Lausberg 229-242).

Aquí tenía lugar la noción de verdad, porque estaba relacionada con captar la benevolencia, además, se supeditaba al discurso moral y se establecía dentro de la distinción entre verosimilitud $\mathrm{y}$ verdad. Los relatos hagiográficos relacionaban la verdad con el acto de ser testigo de vista, si no por sí mismo, por ojos de otros. Este elemento se integraba a las definiciones de historia que circulaban en los siglos XVI y XVII y tenía una profunda raíz medieval. El principio se aplicaba especialmente cuando se trataba una materia que podía ser mal interpretada, como milagros, éxtasis o levitaciones. En las vidas ejemplares estos testimonios abundaban y se soportaban documentalmente, ya fuera por un documento notariado que demostraba, por ejemplo, el carácter incorrupto de un cuerpo, como el de María Gertrudis de Santa Inés, o el testimonio de un testigo de la levitación de Francisca del Niño Jesús (Calvo de la Riba 592; Villamar 315). En cualquiera de los casos, se trataba de dar credibilidad a un acontecimiento, independientemente de su actual veracidad, pues esta era una creencia de la época, una verdad lógica en una sociedad regida por una versión sacralizada de la realidad.

La expresión ser testigo tenía una larga tradición en Occidente: propuesta por los clásicos, se había consolidado a partir del siglo XIII, cuando la historiografía de las cruzadas comenzó a ser escrita por testigos presenciales, lo que incentivó una modificación sobre la "fuente" de conocimiento: la vista sustituía al oído, hasta entonces la fuente más preciada. De este modo, la vista se había convertido en uno de los mecanismos primordiales de la historia medieval, valorada por encima de cualquier otro tipo de información (Zumthor 295) ${ }^{16}$. Las hagiografías se insertaban dentro de esta perspectiva, donde también tenía un

\footnotetext{
${ }^{16}$ Sobre el problema de la verdad en la Edad Media y el significado de la palabra historia, véanse Mendiola (Bernal 57-65), Orcastegui y Sarasa (44-51).
} 


\section{FRONTERAS}

de la fistoria

alto valor lo que se oía; de esta manera Diego Solano dice reconstruir partes de la vida de Antonia Cabañas con la información que le proporcionó la tía de ésta (fol. 11r.), o Fernández construye la vida de Claver con información de quienes lo conocieron (95). El acto de ver era esencial por cuanto confirmaba lo oído, actitud coherente en una sociedad que tejía sus relaciones desde la oralidad y los contenidos bíblicos.

El ser testigo se insertaba dentro del orden medieval. La afirmación de haber "visto y oído" tenía como objetivo proporcionarle un aire verosímil a la narración, al tiempo que legitimaba el valor de la vida ejemplar como historia. Sin embargo, el acto de ser testigo no era un elemento representativo de la argumentación histórica, pues se empleaba para reforzar lo que se narraba. El problema fundamental se centraba en atraer la atención de los lectores desde la transmisión de imágenes vistas para convencerlos de la veracidad de los hechos, suscitando emociones. A esto apelaban frecuentemente los autores cuando mencionaban aspectos íntimos de la vida cotidiana, porque habían tenido alguna relación con sus biografiados, ya fuera como confesores, directores de conciencia, acompañantes o familiares.

Señalarse como testigo, independientemente de serlo o no, proporcionaba la autoridad para afirmar la verdad de la narración, lo cual nos conduce a resaltar los elementos que articulaban la noción. En el discurso de la historia había muchas clases de verdad y formas de entenderla, las cuales se le presentaban al lector a través de las técnicas de representación del discurso. Era un elemento al que también recurrían la filosofía, la lógica y la teología, por lo que en nuestro caso las técnicas de representación se abordaban desde la retórica y la historiografía. La misma dirección del discurso hacia un público definido, orientaba la idea de verdad que ya estaba determinada por la inventio. Veámoslo de esta forma: desde la retórica Valadez dice que la invención "es el descubrimiento anticipado de argumentos verdaderos o verosímiles que hacen plausible una causa" (195), lo que confirma Luis Cabrera de Córdoba desde la historiografía:

Antes, porque es ordinario y cierto el variar, habrá de argumentar sobre probables en la diversidad de los hechos que le refieren, para sacar en limpio la fineza de la verdad y establecer lo que más verdadero o verosímil le pareciese. Vale más en estas cosas la relación que la presencia. [...]. Yo digo, es la historia narración de verdades por hombre sabio, para enseñar a bien vivir (24).

Para crear una verdad hagiográfica había que buscar argumentos que se elegían entre los objetos sobre los que existía un consenso, donde los hechos se 
subordinaban a los valores y los lugares, de manera que lo moral de las vidas ejemplares en el sentido de lo que podían enseñar, se sobreponía al hecho mismo. Esta es la insistencia en argumentar sobre probables, de modo que el relato fuera verdadero, es decir, el aspecto donde se colocaba la fuerza del texto: la verdadera relación o la historia verdadera. Esto pone de manifiesto las dos modalidades de verdad ya mencionadas para la historiografía, de dicto y de re. La primera atribuía el valor de verdad a la narración; la segunda, a objetos, personas o acciones, es decir, al pasado o al presente como objeto (Mignolo 369).

Al tomar la definición de historia de Cabrera de Córdoba que acabamos de reseñar, se encuentran dos elementos más: quién enuncia la narración de verdades (hombre sabio) y el fin mismo de la verdad (enseñar a vivir). Ambas se encontraban en los textos hagiográficos, porque sus autores validaban la verdad de sus palabras desde la defensa que ellos mismos se hacían por medio del stilus humilis, pues en buena medida el criterio de verdad reposaba en quien la enunciaba. Este mismo aspecto les daba la autoridad moral necesaria para presentar su narración como maestra de vida. Por estas características, la verdad no estaba directamente relacionada con el hecho, sino con las condiciones que la soportaban. Aunque el discurso historiográfico de los siglos XVII y XVIII partía del "hecho", éste no tenía ni el valor ni la dimensión temporal que la historiografía del siglo XIX le asignó. La verdad estaba más relacionada con el ideal caballeresco, con la moral y con las autoridades, que con la presentación "objetiva" de la realidad. Debía acentuar lo útil y lo bueno, donde lo primero debía estar sometido a lo segundo, para que fuera persuasiva hacia los modelos de virtud. Finalmente, estas vidas ejemplares se escribían para que se convirtieran en modelos de imitación, y esto era precisamente lo que las validaba como historia.

\section{Bibliografía}

\section{Fuentes primarias}

"Proceso de beatificación del padre Pedro Claver. Su vida, virtudes y milagros" (Roma, 1676). Biblioteca Nacional de Colombia (BN), Bogotá. Libros raros y Manuscritos, libro 281, fols. 1-258.

"Testimonio de diligencias sobre la causa de beatificación y canonización del venerable padre Pedro Claver de la Compañía de Jesús que floreció" 


\section{FRONTERAS}

de la historia

Vol.12 / 2007

(Cartagena de Indias, 1690). Biblioteca Nacional de Colombia (BN), Bogotá. Libros raros y Manuscritos, libro 401, fols. 1-52.

Solano, Diego. "Vida illustre en esclarecidos exemplos de virtud de la modestisima y penitente virgen doña Antonia de Cabañas". Biblioteca Nacional de Colombia (BN), Bogotá. Libros raros y Manuscritos, núm 4.

Palacios, Martín. "Colección de la vida exemplar de la venerable madre Joanna María de San Estevan Religiosa del seraphico monasterio de Santa Clara desta ciudad de Santa Fe de Bogotá del nuebo Reino". Convento de Santa Clara. Bogotá: Manuscrito.

\section{Fuentes secundarias}

Álvarez de Velasco, Gabriel. De la exemplar vida y muerte dichosa de doña Francisca de Zorrilla. Instrucción a la mayor edad que no pudo lograr del todo la pupilar. Alcalá: Colegio de Santo Tomás, 1661.

Andrade, Alonso de. Varones ilustres en santidad, letras, y zelo de las almas de la Compañia de Jesús. t. 6. Madrid: s. e., 1667.

Borja Gómez, Jaime Humberto. Los indios medievales de Pedro de Aguado. Construcción del idólatra y escritura de la historia en una crónica del siglo XVI. Bogotá: Instituto Colombiano de Antropología e Historia; Instituto Pensar, 2002.

Bouza Álvarez, José Luis. Religiosidad contrarreformista y cultura simbólica del barroco. Madrid: Consejo Superior de Investigaciones Científicas, 1990.

Cabrera de Córdoba, Luis. De historia para escribirla y entenderla. Edición, estudio preliminar y notas de Santiago Montero Díaz [1611]. Madrid: Instituto de Estudios Políticos, 1948.

Calvo de la Riba, Pedro Andrés. Historia de la singular vida, y admirables virtudes de la venerable madre sor Maria Gertrudis Theresa de Santa Ines Religiosa professa en el sagrado monasterio de Santa Inés, de Monte Policiano, fundado en la ciudad de Santa Fe, del Nuevo Reino de Granada. Madrid: Phelipe Milllán, 1752. 
Cassani, José, S. J. Historia de la Provincia de la Compañia de Jesus del Nuevo Reyno de Granada en la América. Madrid: Manuel Fernández, 1741.

Certeau, Michel de. La escritura de la historia. México: Universidad Iberoamericana, 1994.

Curtius, Ernst. Literatura europea y Edad Media Latina. México: Fondo de Cultura Económica, 1975.

Delehaye, Hippolyte. Les passions des martyrs et les genres litteraires. Bruxelles: Bureaux de la Société del Bollandistes, 1921.

Dubois, Dom Jacques y Jean Loup Lemaitre, Sources et méthodes de l’hagiographie médiévale. París: Cerf, 1993.

Durán Rodríguez, María Norma. "Ascesis, culpa y subjetividad. Un estudio de la vida de F. Sebastián de Aparicio escrita por fray Juan de Torquemada". Trabajo de grado de doctorado. Universidad Iberoamericana, 2004.

Fernández, Josef. Apostólica y penitente vida de el v. p. Pedro Claver de la Compañía de Jesús. Zaragoza: Diego Dormer, 1666.

Flórez de Ocariz, Juan. Libro primero de las genealogías del Nuevo Reino de Granada. Madrid: s. e., 1674. Edición facsímilar. Bogotá: Instituto Caro y Cuervo, 1990.

Gómez Restrepo, Antonio. Historia de la literatura colombiana. Literatura ascética y religiosa. Bogotá: Biblioteca Nacional de Colombia, s. f.

Koselleck, Reinhart. Futuro pasado. Para una semántica de los tiempos históricos. Barcelona: Paidós, 1993.

Lausberg, Heinrich. Manual de retórica literaria. t. 1. Madrid: Gredos, 1970.

Lavrin, Asunción y Rosalva Loreto, eds. La escritura femenina en la espiritualidad barroca novohispana. Siglos XVII y XVIII. México: Universidad de las Américas; Archivo General de la Nación, 2002.

Loreto, Rosalva. "Escrito por ella misma. Vida de la madre Francisca de la Natividad". La escritura femenina en la espiritualidad barroca 


\section{FRONTERAS}

de la historia

Vol.12 / 2007

novohispana. Siglos XVII y XVIII. Eds. Asunción Lavrin y Rosalva Loreto. México: Universidad de las Américas; Archivo general de la Nación, 2002. 24-67.

Mendiola, Alfonso. Bernal Díaz del Castillo, verdad romanesca y verdad historiográfica. México: Universidad Iberoamericana, 1992.

- Retórica, comunicación y realidad. La construcción retórica de las batallas en las crónicas de la Conquista. México: Universidad Iberoamericana, 2003.

Mercado, Pedro. El cristiano virtuoso, con los actos de todas las virtudes que se hallan en la santidad. Madrid: s.e., 1673.

Mignolo, Walter. "El metatexto historiográfico y la historiografía indiana". Modern Lenguages Notes 96. 2 (1981): 358-402.

Momigliano, A. Ensayos de historiografia antigua y moderna. México: Fondo de Cultura Económica, 1993.

Montero Díaz, Santiago. "La doctrina de la historia en los tratadistas del Siglo de Oro". De historia para escribirla y entenderla. Luis Cabrera de Córdoba [1611]. Madrid: Instituto de Estudios Políticos, 1948.

Orcastegui, Carmen y Esteban Sarasa. La historia en la Edad Media. Madrid: Cátedra, 1991.

Piedrahíta, Lucas Fernández de. Historia general de las conquistas del Nuevo Reyno de Granada [1665]. Bogotá: Imprenta de Medardo Rivas, 1881.

Porqueras Mayo, Alberto. El prólogo como género literario. Madrid: Consejo Superior de Investigaciones Históricas, 1957.

Rubial, Antonio. La santidad controvertida. Hagiografia y conciencia criolla alrededor de los venerables no canonizados de Nueva España. México: Universidad Nacional Autónoma de México; Fondo de Cultura Económica, 1999.

Ruffinatto, Aldo. Hacia una teoría semiológica del relato hagiográfico. 8 oct. 2005. 
$<$ http://www.vallenajerilla.com/berceo/ruffinatto/semiologiahagiografic o.htm>.

Sánchez Lora, José Luis. "Hechura de santo: proceso y hagiografía". Grafias del imaginario. Representaciones culturales en España y América (siglos XVI-XVIII). Comps. Carlos Alberto González y Enriqueta Vila Vilar. México: Fondo de Cultura Económica, 2003. 336-352.

- Mujeres, conventos y formas de la religiosidad barroca. Madrid: Fundación Universitaria Española, 1988.

Sevilla, Isidoro de. Etimologías. Libros I y II. Madrid: Biblioteca de Autores Cristianos, 1994.

Simón, Pedro. Noticias historiales de las conquistas de Tierra Firme en las Indias Occidentales. 7 t [1624]. Bogotá: Banco Popular, 1981.

Solís de Valenzuela, Pedro. Epitome breve de la vida y muerte del ilustrissimo dotor don Bernardino de Almansa. Madrid: Diego Dias de la Correa, 1647.

Splendiani, Anna María y Tulio Aristizábal. Proceso de beatificación y canonización de san Pedro Claver. Bogotá: Universidad Javeriana, 2002.

Spiegel, Gabrielle. "Historia, historicismo y lógica social del texto en la Edad Media". Historia y literatura. François Perus. México: Instituto Mora, 1994.

Stica, Sandro. Saints. Studies in Hagiography. Nueva York: University of the State of New York, 1996.

Toro, Juan Bautista de. El secular religioso. Para consuelo y aliento de los que viviendo en el siglo pretenden lograr el cielo. Madrid: Francisco del Hierro, 1722.

Valadez, Diego. Rethorica cristiana [1579]. México: Universidad Nacional Autónoma de México; Fondo de Cultura Económica, 1989. 


\section{FRONTERAS}

de la historia

Villamor, Pedro Pablo de. Vida y virtudes de la venerable madre Francisca María de el Niño Jesús, religiosa profesa en el Real Convento de Carmelitas Descalzas de la ciudad de Santa Fe, dedicada a la serenísima reyna de los Angeles María Santísima de el Carmen. Madrid: Juan Martínez de Casas, 1723.

Zamora, Alonso de. Historia de la Provincia de san Antonino del Nuevo Reino de Granada. [1700]. Bogotá: Instituto de Cultura Hispánica, 1980.

Zumthor, Paul. La medida del mundo. Representación del espacio en la Edad Media. Madrid: Cátedra, 1994.

Fecha de recepción: $1^{\circ}$ de junio de 2007.

Fecha de aprobación: 30 de julio de 2007. 